\title{
SEASONAL DECLINES IN OFFSPRING FITNESS AND SELECTION FOR EARLY REPRODUCTION IN NYMPH-OVERWINTERING GRASSHOPPERS
}

\author{
KeITH LANDA ${ }^{1}$ \\ Department of Biology, University of Michigan, Ann Arbor, MI 48109 USA
}

\begin{abstract}
In this study, I examine the effects of natural and experimentally induced variation in life cycle timing on offspring fitness in Arphia sulphurea and Chortophaga viridifasciata, to understand the selective pressures shaping phenology in these two species of nymph-overwintering grasshoppers. Because these species lack embryonic diapause, hatching varies over a two month range under natural conditions. I used a cold treatment to delay hatching of some egg pods and extend the natural range of hatching dates. Due to the shorter time for growth and poorer growing conditions late in the fall, late-hatching nymphs of both species grew to a smaller size before winter and suffered higher overwinter mortality, compared to early nymphs. In addition, late nymphs that did survive the winter became reproductive later in the following year's breeding season. Sizedependent mortality of offspring during the winter is a strong selective pressure favoring early reproduction in these species. Female adult life history traits appear responsive to the seasonal declines in offspring fitness, in that late-maturing females began reproducing sooner after adult maturation and reproduced at a more rapid rate, even at the expense of having shorter adult longevity and producing fewer total egg pods. Experimental manipulations were crucial in understanding the fitness consequences of intrapopulation variation in the timing of specific life-cycle events for these species.
\end{abstract}

Key words. -Age of maturation, body size, grasshoppers, juvenile survival, life cycle timing, phenology, reproductive rate, seasonality.

Received January 16, 1991. Accepted June 28, 1991.

Beginning with the papers of Lande and Arnold (1983) and Arnold and Wade $(1984 a, 1984 b)$, there has been an explosion of interest in using statistical methods to measure natural selection in the field. Recent issues of Evolution contain numerous papers using these approaches (e.g., Campbell, 1989; Schemske and Horvitz, 1989; Rauscher and Simms, 1989; Scheiner, 1989; Jayne and Bennett, 1990; Smith, 1990; Weis and Gorman, 1990), and papers debate the relative merits of various statistical techniques (Arnold, 1986; Koening and Albano, 1987; Downhower et al., 1987; Hubbell and Johnson, 1987; Mitchell-Olds and Shaw, 1987; Schluter, 1988; Crespi and Bookstein, 1989; Wade and Kalisz, 1989). Although these statistical approaches are powerful tools for measuring selection, they have limitations which must be kept in mind. Because they deal with correlations of relative fitness with phenotypic traits, it is often difficult to determine what factor is actually causing the changes in phenotypic distributions (Wade and Kalisz, 1990). A corol-

\footnotetext{
' Present address: Department of Biology, Indiana University, Bloomington, IN 47405 USA.
}

lary of this is that the measured selection gradient may actually be due to selection operating on other correlated phenotypic traits, which may not have been measured in the analysis. Second, the range of phenotypic variation may be insufficient to determine the shape of the fitness function (Schluter, 1988). Experimental manipulation of phenotypic distributions provides a complimentary approach to investigating selection that alleviates some of these limitations. Recent papers using experiments to measure selection in the field include Mallet and Barton (1989) and Sinervo (1990).

Selection on life cycle timing illustrates these points. The timing of specific life cycle events is an important source of adaptation to seasonal variation in resource abundance and in the favorability of the abiotic and biotic environment (Taylor, 1980a, 1980b; Roff, 1983; Tauber et al., 1986; Taylor and Karban, 1986) and can constrain life-history evolution (Giesel, 1976; Boyce, 1979; Hastings, 1984). Offspring survival and/or subsequent reproduction in numerous organisms varies with date of hatching or germination (e.g., Feeny, 1970; Baskin and Baskin, 1972; Dixon, 1976; Cook, 1980; 
Marks and Prince, 1981; Lacey, 1982; Ohgushi, 1986; Kalisz, 1986). These studies have observed either stabilizing selection or selection for early hatching/germination. However, offspring quality can vary seasonally (e.g., Wellington, 1965; Pickford, 1976; Harvey, 1977; Cavers and Steel, 1984; Forrest, 1986). It is not clear, therefore, whether observed seasonal changes in offspring fitness are due to the timing of emergence or correlated seasonal changes in offspring quality. In addition, the shape of the fitness function will depend on the amount of available variation in hatching date. If stabilizing selection on hatching time has been strong (a likely situation), then there may be insufficient variation in hatching time to observe an effect on offspring fitness. Manipulation of hatching time can increase the range of variation available, and uncouple any seasonal correlations between hatching time and offspring quality. In this paper I use experimental manipulations of life cycle timing in two species of grasshoppers, Arphia sulphurea (Fabricus) and Chortophaga viridifasciata (DeGeer) (Orthoptera: Acrididae), to investigate how offspring fitness varies with hatching date, and whether females show any life history response to such seasonal changes in offspring fitness.

$A$. sulphurea and $C$. viridifasciata have interesting life cycles for the study of phenological adaptations to seasonal environments. Unlike the majority of Nearctic grasshoppers, which overwinter as eggs (Otte, 1981, 1984), A. sulphurea and C. viridifasciata pass the winter as late instar nymphs, frozen beneath leaf litter (Cantrall, 1943; Alexander, 1967). In egg-overwintering grasshoppers, eggs hatch during the spring, nymphs develop during the spring and summer and adults are active through late summer and fall. In contrast, for $A$. sulphurea, $C$. viridifasciata and other nymphoverwintering grasshoppers, warming spring temperatures thaw the overwintering nymphs, which then undergo one or two molts to become adults. Adults are present early in the season and reproduce from late spring into the summer. Eggs hatch the same summer they are laid and nymphs undergo three to four molts before the onset of winter.

\section{Materials AND Methods}

$A$. sulphurea and $C$. viridifasciata used in this study were from populations located at the Edwin S. George Reserve, an enclosed natural area in southeastern Michigan. In order to follow the development and reproduction of known individuals, grasshoppers were collected from the field in spring, 1984, and they and their progeny were maintained in small field cages, exposed to ambient temperature, sunlight and photoperiod (Landa, 1989). The field cages were set up at the University of Michigan's Matthaei Botanical Gardens, in Ann Arbor, Michigan.

In addition to observing natural variation in oviposition, hatching, survival and reproduction, two experimental manipulations of life cycle timing were done. First, the hatching of some egg pods was delayed by refrigeration. This not only extended the natural range in variation for hatching, but also allowed separation of fitness effects due to date of hatching from potential effects resulting from the seasonal increases in offspring size displayed by these species (Landa, 1989). Second, a subset of overwintering nymphs was brought into a heated greenhouse in late winter, to assess survival. I examined adult life-history traits of these individuals to see how they were affected by the early initiation of spring growth. In addition, egg pods from these early adults were used to extend the analysis of the relationship between oviposition date and date of hatching, and to examine phenotypic plasticity for offspring size (Landa, 1989), but offspring from these pods were not monitored during the following year to determine fitness consequences of early hatching.

\section{Oviposition Phenologies and Hatching}

To determine the distribution of oviposition dates exhibited under natural conditions by $A$. sulphurea and $C$. viridifasciata, random samples of individuals were collected from field populations of these two species between May 12 to May 22, 1984, and maintained in an outdoor screenhouse. As females matured, they were paired with males in individual oviposition cages. Approximately every three days, each adult female was transferred to a new oviposition 
cage and the sand of the old cage was sifted to check for the presence of egg pods. The midpoint of the time interval between cage changes was taken as the date of oviposition for any egg pods (usually only one or none) that were found in a cage. Analysis of variance was used to test for differences in oviposition phenologies between the two species.

Control, delayed, and early egg pods were followed to determine seasonal changes in the relationship between oviposition date and hatching phenology. Control and early egg pods were incubated in small windowscreen enclosures under screenhouse conditions (Landa, 1989), immediately after their collection from the oviposition cages. Delayed egg pods had their development suspended by keeping them in a $4^{\circ} \mathrm{C}$ cold room for four weeks, prior to their incubation under screenhouse conditions. Oviposition dates for delayed egg pods were adjusted by adding 28 days to the recorded oviposition date. Egg pod cages were observed at least daily to check for hatching. Embryonic development time for a pod was calculated as the difference between hatching date and oviposition date. Mean temperature experienced between oviposition and hatching was calculated separately for each egg pod, using daily high/low temperature records.

Because the relationship between oviposition date and hatching date was curvilinear, I used the GLM procedure of SAS to fit second-order polynomial regressions to the data, and then used Type I sums of squares (SAS, 1985) to test whether egg pod treatment explained any additional variance in hatching date. As there were no differences in development time or hatching phenology between control egg pods from 1984 and 1985 , these pods were lumped together in the analyses. To test whether the refridgeration treatment had any effects on embryonic development, I used analysis of covariance to compare the number of hatchlings and mean hatchling dry weight between delayed and control egg pods from 1984 , with oviposition date as the covariate.

\section{Fall Growth and Overwinter Survival}

The mean weight of nymphs from each hatched pod was recorded every four to five days, until early November. At that time nymphs were placed into overwintering cages, which provided ground cover for the quiescent nymphs and which were exposed to ambient temperatures and snowfall (Landa, 1989). Surviving nymphs were recovered the following spring, weighed and maintained in field cages until they molted to adults. Thirty randomly selected overwintering cages were brought into a greenhouse in mid-February, 1985, and surviving nymphs recovered and weighed. These nymphs were maintained in the greenhouse until they molted, at which time they were placed outside in oviposition cages.

Nymphal weight at the time of placement into the overwintering cages was plotted against date of hatching for control and delayed nymphs of each species. Analysis of covariance, with hatching date as covariate, was used to test whether egg pod treatment had any effect on prewinter weight, and whether individuals of the two species differed in prewinter weight, for a given hatching date. Only control and delayed nymphs that overlapped in hatching dates were used in the analysis of treatment effects. As $A$. sulphurea and $C$. viridifasciata had similar ranges of hatching dates, all the data were used in the analysis of species differences.

To display seasonal changes in growth, cohorts of nymphs were combined into five groups for $A$. sulphurea and four groups for $C$. viridifasciata, based on date of hatching. Means and standard deviations for weight were calculated over 15 day intervals for each group and plotted against age to show each group's growth trajectory. Because insect growth is highly temperature dependent, weight data were also analyzed as a function of the number of degree-days accumulated. A baseline of $15^{\circ} \mathrm{C}$ was chosen for degree-day calculations. This baseline is similar to values used in other grasshopper studies (Hilbert and Logan, 1983; Whitman, 1986; Dingle et al., 1990) and resulted in near linear relationships between weight and accumulated degree-days.

Overwinter survival was analyzed in terms of nymphal prewinter weight. Nymphs were divided into weight classes of $0-20$, 20-40, 40-80, 80-120, and greater than 120 $\mathrm{mg}$, and the number of surviving and dead 


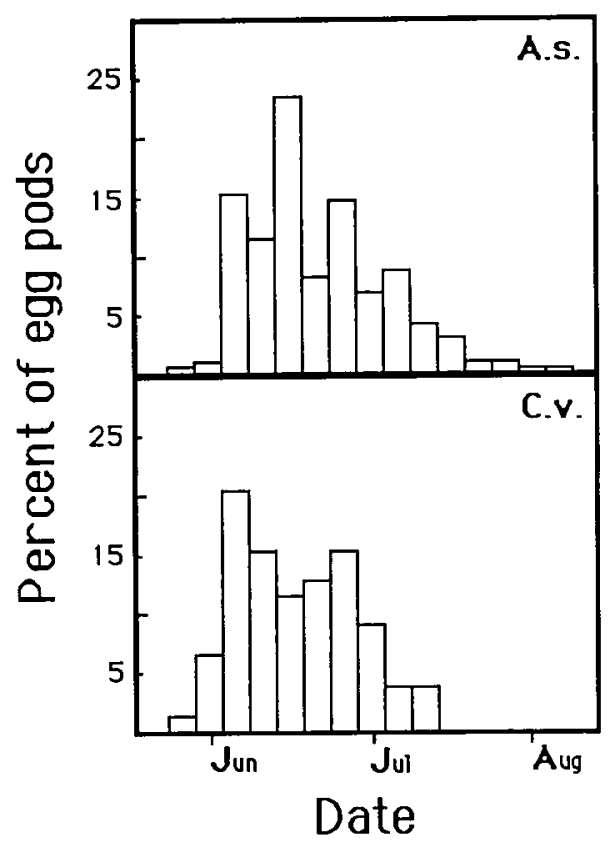

FIG. 1. Oviposition phenologies for $A$. sulphurea and $C$. viridifasciata under natural conditions. Oviposition dates were grouped into five day intervals. Tick marks on the $\mathrm{x}$ axis indicate the first day of each month. Mean oviposition date for A. sulphurea was June 19 , with a standard deviation of 12.5 days and skewness of +0.68 . Corresponding values for $C$. viridifasciata were June $15,10.8$ days and +0.33 .

nymphs tallied for each weight class. Chisquare analyses were done for each species to test the effect of prewinter size on survival. Cochran-Mantel-Haenszel (CMH) statistics were used to test for differences in survival between control and delayed nymphs and for differences between species, after adjusting for the effects of size on survival (SAS, 1985). CMH statistics were also used to compare survival of nymphs at midwinter with survival through to spring. Postwinter weight was regressed against prewinter weight to examine changes in body size of surviving nymphs during the winter.

\section{Adult Life History Traits}

During spring, 1985, field cages were checked daily for newly molted adults. Adult molting date was recorded for all individuals and pronotum length, which is highly correlated with weight (Dean, 1982), was measured as an index of adult body size.
Adults were set up in oviposition cages and data were collected for each female on the date of oviposition of all egg pods produced, total number of egg pods produced and date of death. Two measures of female reproductive activity were analyzed: the duration of the teneral period between adult molting and the production of the first egg pod, and the mean number of days between successive egg pods. Nymphal hatching rate from the 1985 pods was highly variable due to a fungal infection in the egg pod cages, and so data on total number of offspring were not analyzed. Adult longevity was calculated as the difference between date of death and molting date.

I examined the effects of hatching date and spring treatment (early initiation of growth versus controls) on the timing of adult maturation and adult body size. Female reproduction and survival were analyzed with respect to both spring treatment and molting date, to determine whether early and late females differed in their life history characteristics. For simplicity, data on female reproduction and survival are presented as comparisons between early and control groups, but similar trends were seen within groups as a function of molting date. So few of the individuals for which adult life history traits were measured came from delayed hatching treatment, and delayed nymphs differed so little from controls in their juvenile growth and survival, that this factor was not included in any of the analyses of adult life history traits.

\section{RESULTS}

\section{Oviposition Phenologies and Hatching}

Although oviposition phenologies were broadly similar for the two species (Fig. 1), C. viridifasciata females reproduced significantly earlier than $A$. sulphurea females (ANOVA, $F_{1,408}=6.49, P=0.011$ ). Oviposition began in late May and rose to peak levels during the first half of June. The distribution of oviposition dates was positively skewed for both species, reflecting early peaks of oviposition. Oviposition by $C$. viridifasciata peaked 10 days earlier than for A. sulphurea, and terminated 15 days earlier. Ranges of oviposition dates under 


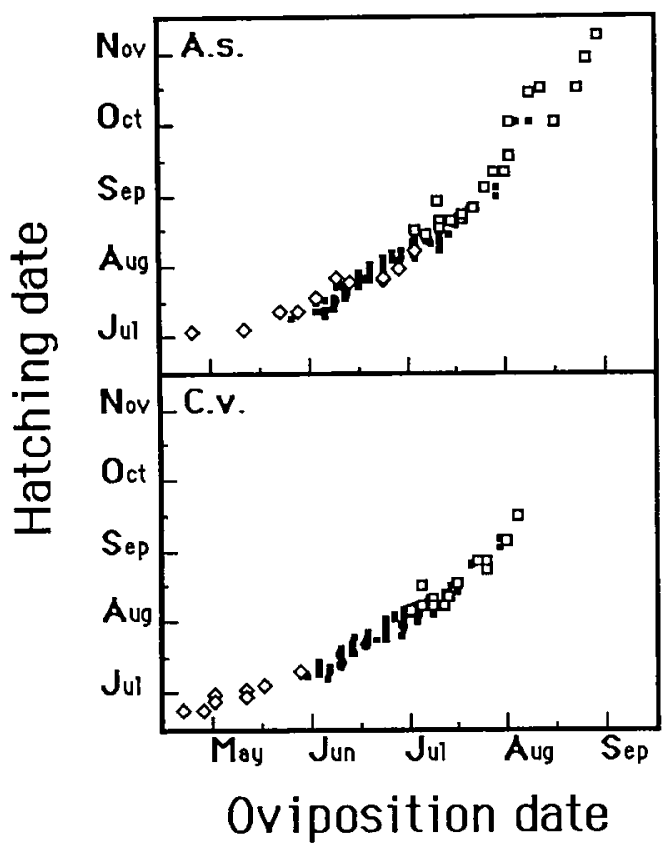

FIG. 2. Hatching phenologies for $A$. sulphurea and $C$. viridifasciata. Major tick marks on the axes correspond to the first day of each month. Solid squares represent control egg pods from 1984 and 1985, open squares are delayed egg pods from 1984 and open triangles represent egg pods from early females in 1985.

screenhouse conditions correspond with field phenologies for adults of these species (Cantrall, 1943; Gangwere et al., 1976).

Hatching date was highly correlated with oviposition date for both species (Fig. 2), while egg pod treatment had little or no effect. Oviposition date explained $96.2 \%$ of the variance in hatching date for $A$. sulphurea $\left(F_{2,163}=2,176.7, P=0.0001\right)$ and $96.6 \%$ for $C$. viridifasciata $\left(F_{2,151}=2,153.3, P=\right.$ 0.0001 ). Treatment only explained $0.2 \%$ of the hatching date variance for $A$. sulphurea $\left(F_{2,163}=3.94, P=0.02\right)$ and none of the residual variance for $C$. viridifasciata. $C$. viridifasciata egg pods hatched earlier, for a given oviposition date, than those for $A$. sulphurea $\left(F_{1,320}=106.26, P=0.0001\right)$.

The nonlinear relationship between oviposition and hatching date resulted from seasonal changes in embryonic development time. Pods laid in June and July took $41.5 \pm 3.4$ days to develop for $A$. sulphurea and $37.7 \pm 3.6$ days for $C$. viridifasciata. Both earlier and later pods had longer embryonic development times. The longer de-

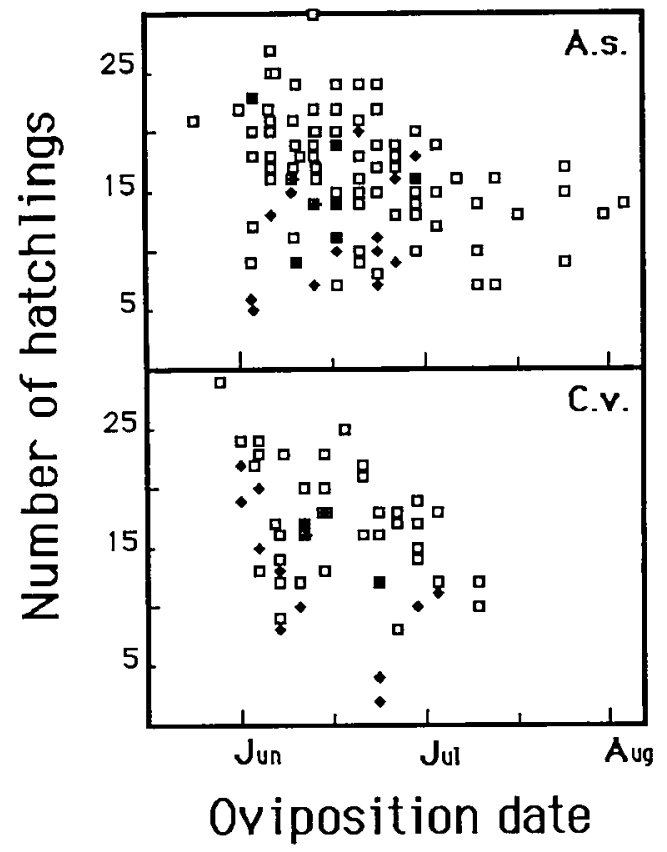

FIG. 3. Number of nymphs per pod, as a function of oviposition date and treatment, for 1984 egg pods. Major tick marks on the $\mathrm{x}$ axis correspond to the first day of each month. Data for control egg pods are given by the open squares, while delayed egg pods are represented by the solid diamonds.

velopment times seen for embryos of early and late pods, compared with midseason pods, were associated with cooler average temperatures during development. Development time increased 3.9 days per degree Celcius temperature decrease for $A$. sulphurea $\left(R^{2}=63.4 \%, P=0.0001\right)$ and 3.5 days for $C$. viridifasciata $\left(R^{2}=55.0 \%, P=\right.$ $0.0001)$. Most natural oviposition coincided with this period of minimum development time (Figs. 1 and 2).

The number of nymphs per pod declined seasonally for both species (Fig. 3). Delayed pods produced fewer nymphs than control pods, but there was no difference in hatchling dry weight between delayed and control pods (Table 1). A. sulphurea and $C$. viridifasciata produced similar numbers of nymphs per pod, but $C$. viridifasciata hatchlings were, on average, $36 \%$ smaller.

\section{Fall Growth and Overwinter Survival}

The size attained by nymphs before the onset of winter declined precipitously with 
TABLE 1. Analysis of variance for the effect of refrigeration treatment on hatchling dry weight in $A$. sulphurea and $C$. viridifasciata.

\begin{tabular}{lcc}
\hline \hline & A. sulphurea & C. viridifasciata \\
\hline Control hatchlings & \multicolumn{2}{c}{} \\
Mean weight (mg) & 2.14 & 1.36 \\
Std deviation & 0.27 & 0.13 \\
$n$ & 94 & 42 \\
Delayed hatchlings & & \\
Mean weight (mg) & 2.14 & 1.31 \\
Std deviation & 0.20 & 0.22 \\
$n$ & 16 & 14 \\
ANOVA & & \\
$F$ & 0.00 & 0.87 \\
$d f$ & 1,108 & 1,54 \\
$P$ & 0.99 & 0.36 \\
\hline
\end{tabular}

date of hatching (Fig. 4). A. sulphurea nymphs which hatched in early July weighed $100-150 \mathrm{mg}$ by November, while those hatching in September or later weighed less than $20 \mathrm{mg}$. $C$. viridifasciata nymphs showed a similar response, although they grew to a smaller prewinter weight than $A$. sulphurea nymphs, for a given hatching date $\left(F_{1,160}=\right.$ $113.18, P=0.0001)$. Control and delayed A. sulphurea nymphs did not differ in size, beyond differences attributable to hatching date $\left(F_{1,24}=0.34, P=0.56\right)$. Delayed $C$. viridifasciata nymphs, however, were somewhat smaller than control nymphs of the same hatching date $\left(F_{1,14}=5.24, P=0.038\right)$.

The smaller prewinter size of late hatching nymphs resulted from a combination of two factors. Late nymphs, by definition, had less time to grow before the onset of winter, and they had lower growth rates (Fig. 5a). The declines in growth rates of late hatching nymphs were associated with lower temperatures later in the fall growing season. For both species, weight was positively correlated with accumulated degree-days (Fig. $5 b$ ). A. sulphurea nymphs increased weight with accumulated degree-days more quickly than did $C$. viridifasciata nymphs, which accounts for the smaller prewinter weights as a function of hatching date for C. viridifasciata nymphs (Fig. 4). Early and late season cohorts of $A$. sulphurea nymphs showed no significant differences in their growth responses to temperature. For C. viridifasciata, however, early nymphs grew

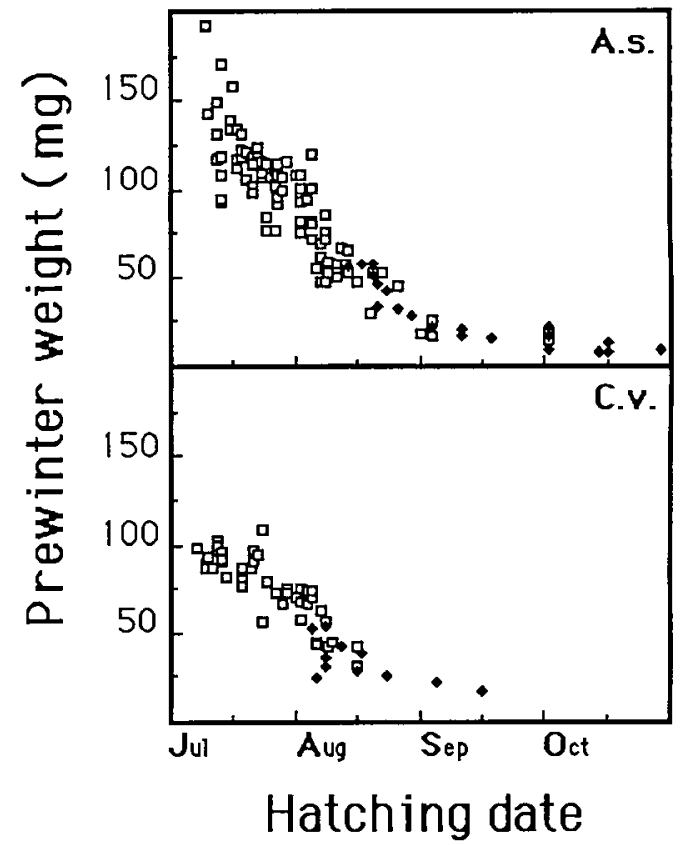

FIG. 4. Prewinter size as a function of hatching date and egg pod treatment. Mean weight of each cohort was taken in early November, just before the nymphs were placed outside in overwintering cages. Major tick marks on the $x$ axis correspond to the first day of each month. Data for control egg pods are given by the open squares, while delayed egg pods are represented by the solid diamonds.

significantly more slowly, on a temperatureadjusted basis, than did late nymphs. As a consequence of the seasonal changes in temperature response in $C$. viridifasciata and the lack of such seasonal changes in $A$. sulphurea, age-based growth trajectories differed less among early and late cohorts for $C$. viridifasciata than for $A$. sulphurea (Fig. $5 a)$ and the greatest divergence in prewinter body sizes between the two species occurred for early hatching nymphs (Fig. 4).

Larger nymphs had a greater probability of surviving the winter than smaller nymphs (Fig. 6). For A. sulphurea, no nymphs weighing less than $40 \mathrm{mg}$ survived the winter while those larger than $40 \mathrm{mg}$ had a $25 \%$ survival $\left(\chi^{2}=11.98, d f=4, P=0.0001\right)$. For $C$. viridifasciata, survival of nymphs less than $40 \mathrm{mg}$ was again near zero, while larger nymphs had a $40 \%$ survival $\left(\chi^{2}=\right.$ 18.72, $d f=3, P=0.0001)$. Delayed and control nymphs did not differ in their probability of survival (A. sulphurea: $P=0.32$; 

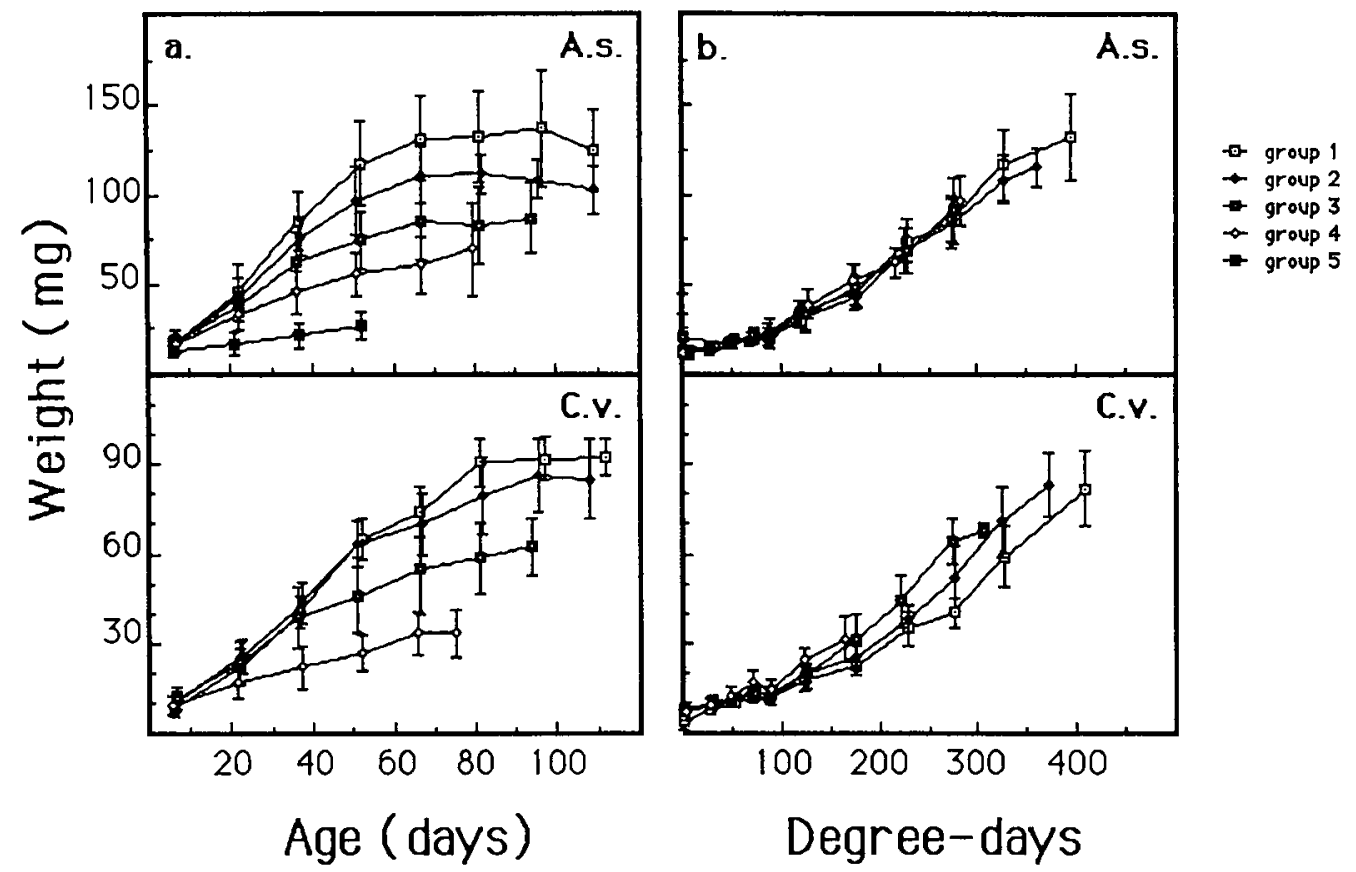

Fig. 5. Fall growth trajectories. Figure $5 a$ plots weight against absolute age in days while Figure $5 b$ plots weight against accumulated degree-days above a baseline of $15^{\circ} \mathrm{C}$. For $A$. sulphurea, group 1 includes all cohorts that hatched before July 22, group 2 those between July 23 and July 31, group 3 those between August 2 and August 10, group 4 those between August 12 and August 24 and group 5 those after August 26 . For $C$. viridifasciata, group 1 includes all cohorts that hatched before July 16, group 2 those between July 20 and July 31, group 3 those between August 2 and August 13 and group 4 those after August 16. Later groups have less time to grow before winter and so their age-based trajectories end earlier. The initial slopes of the age-based trajectories indicate how growing conditions decline during the season.

C. viridifasciata: $P=0.78$ ). . viridifasciata survival at a given size was significantly greater than for $A$. sulphurea (CMH statistic $=13.55, d f=1, P=0.0001$ ).

Much of the overwinter mortality occurred late in the winter. A significantly higher proportion of nymphs were alive when brought into the greenhouse in February, compared with those left in field cages until spring (A. sulphurea: $\mathrm{CMH}$ statistic $=68.73, P=0.0001 ; C$. viridifasciata $: \mathrm{CMH}$ statistic $=4.63, P=0.031$ ). Midwinter $A$. sulphurea nymphs had a $68 \%$ survival, while C. viridifasciata nymphs had an $89 \%$ survival.

Body sizes of surviving nymphs decreased only slightly over winter (Fig. 7). Regressions of postwinter weight on prewinter weight had slopes not significantly different from 1 and intercepts not significantly different from 0 . A. sulphurea nymphs lost $6 \pm 18 \%$ of their weight over winter, while $C$. viridifasciata nymphs lost $9 \pm 16 \%$. Delayed and control nymphs did not differ in their weight change over winter $(A$. sulphurea: $F_{1,29}=0.06, P=0.81 ; C$. viridifasciata: $F_{1,25}=0.32 ; P=0.58$ ).

\section{Adult Life History Traits}

Control female nymphs which hatched later during the 1984 season became adults significantly later in 1985 than earlierhatching females (Fig. 8). Each day of increase in hatching date resulted in a delay in the timing of adult molting of 0.64 days for $A$. sulphurea females $\left(F_{1,15}=14.36, P\right.$ $=0.0018$ ) and 0.34 days for $C$. viridifasciata females $\left(F_{1,14}=4.67, P=0.048\right)$. For males of both species, adult molting date was not significantly correlated with hatching date, although late-hatching $A$. sulphurea males had a slight tendency to molt later than early hatching $A$. sulphurea males $\left(F_{1.9}=3.14, P\right.$ 


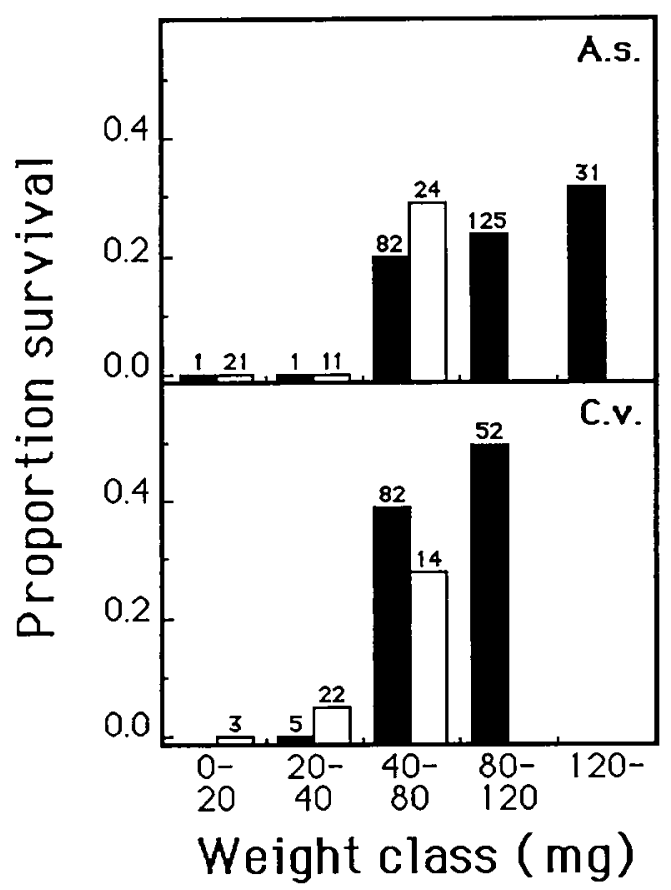

FIG. 6. Size-dependent overwinter survival. Cohorts of nymphs were grouped into categories based on their mean prewinter weight, and the proportion surviving after the winter plotted for each size category. Data for control nymphs are given by the solid bars, while survival of delayed nymphs is given by the open bars. The numbers over the bars give the number of nymphs in each category. Size and treatment categories which had no individuals have missing bars.

$=0.11$ ). For both sexes of both species, late nymphs took a shorter absolute time to go from hatching to adult than early nymphs. Only for $C$. viridifasciata males, however, was this decrease in juvenile development time among later nymphs sufficient to overcome completely the original differences in life cycle timing resulting from late hatching. Early initiation of spring growth by midFebruary transfer to the heated greenhouse resulted in the early nymphs molting about a month earlier than controls.

Adult body size was unrelated to hatching date for all combinations of male and female $A$. sulphurea and $C$. viridifasciata (Fig. 9). Early initiation of spring growth increased body size marginally for $A$. sulphurea males $\left(F_{1,31}=4.34, P=0.046\right)$, but had no effect on body size for any other group. Early $A$. sulphurea males were $3.2 \%$ larger than controls.

Female life history traits were affected by

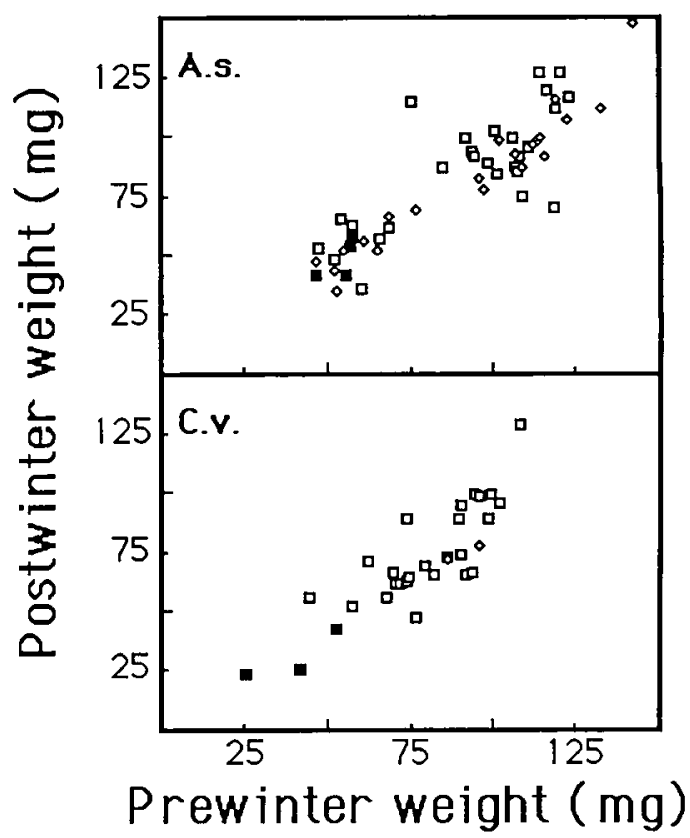

FIG. 7. Comparison of weight changes over the winter. The squares plot early spring weight against weight at the beginning of November. Open squares are for control nymphs while closed squares are for delayed nymphs. Open triangles give the weights of early nymphs at the time they were brought into the greenhouse in February.

maturation date (Fig. 10). Late maturing $A$. sulphurea females began reproducing sooner after becoming adult $\left(F_{2,22}=4.91, P=\right.$ $0.017)$ and produced egg pods at a more rapid rate $\left(F_{2,22}=3.66, P=0.042\right)$, compared to early maturing females. Early $A$. sulphurea females had a longer adult longevity $\left(F_{2,22}=30.95, P=0.0001\right)$, however, and as a consequence, produced more egg pods over their lifespan $\left(F_{2,22}=7.87, P=\right.$ $0.0026)$. C. viridifasciata females showed the same patterns for interpod interval $\left(F_{2,15}=\right.$ $6.11, P=0.011)$, adult longevity $\left(F_{2,15}=\right.$ 29.46, $P=0.0001)$ and total number of egg pods $\left(F_{2,15}=8.00, P=0.0043\right)$. The onset of reproduction after adult molting did not differ between early and late maturing $C$. viridifasciata females $\left(F_{2,15}=0.73, P=0.50\right)$.

\section{Discussion}

\section{Seasonal Declines in Offspring Fitness}

Size-dependent overwinter mortality is an important factor resulting in seasonal declines in offspring fitness for $A$. sulphurea 


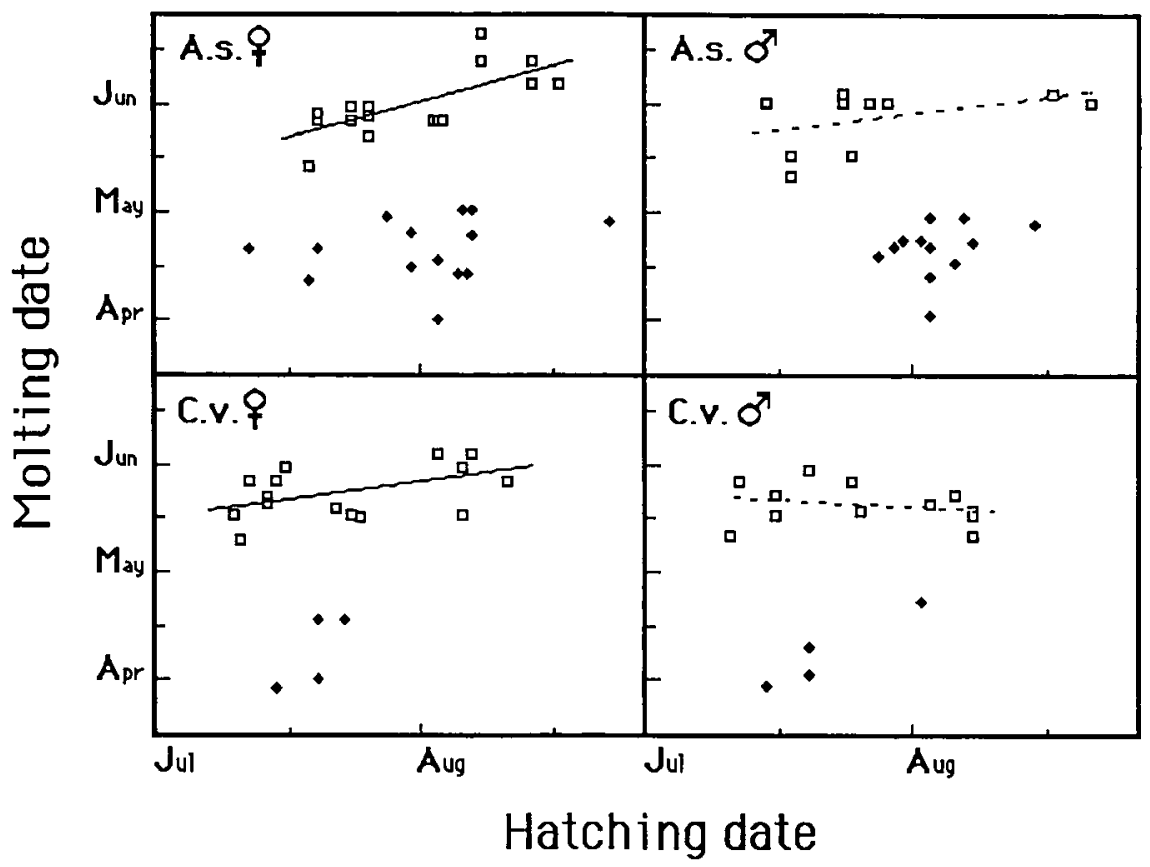

Fig. 8. Adult molting date as a function of hatching date and spring growing treatment. Open squares represent control individuals while solid diamonds give data for individuals brought into the greenhouse in midwinter. Regression lines are given for control individuals: solid lines represent significant regressions while dashed lines indicate nonsignificant regressions.

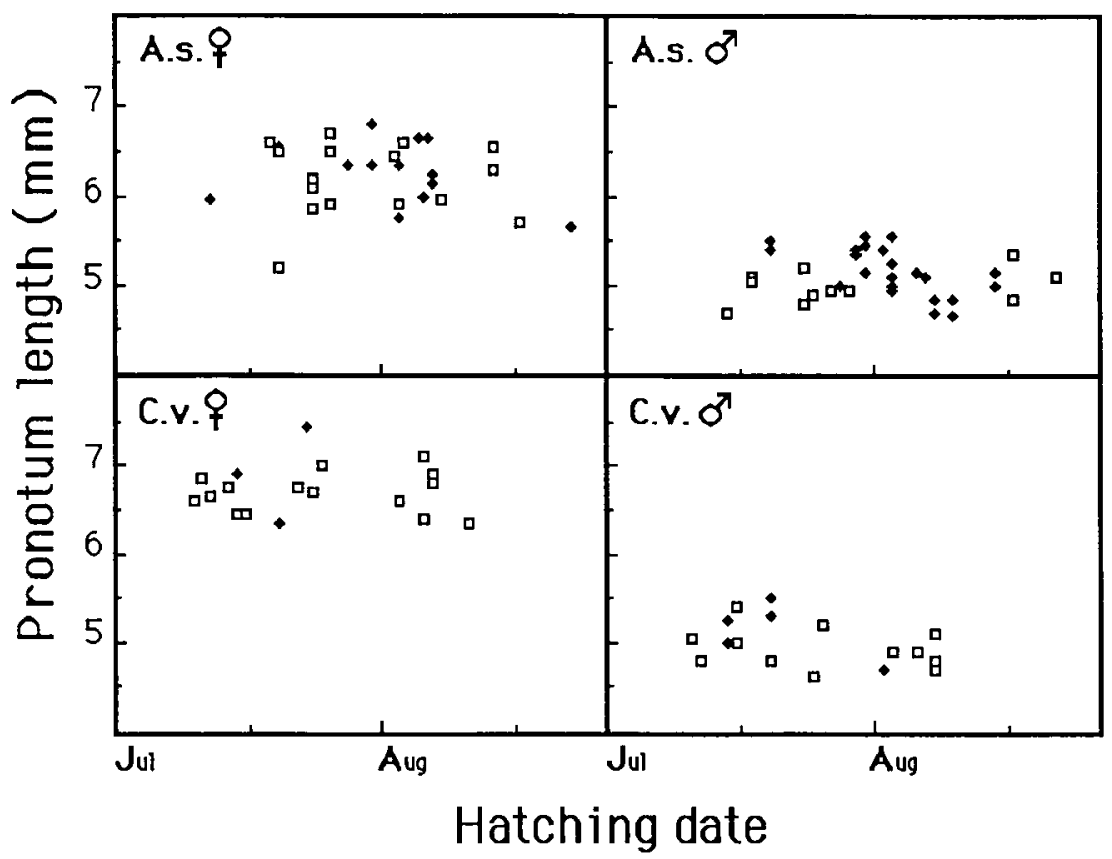

FIG. 9. The effect of hatching date and spring growing conditions on adult body size. Pronotum length was measured as an index of body size. Symbols are as in Figure 8. 


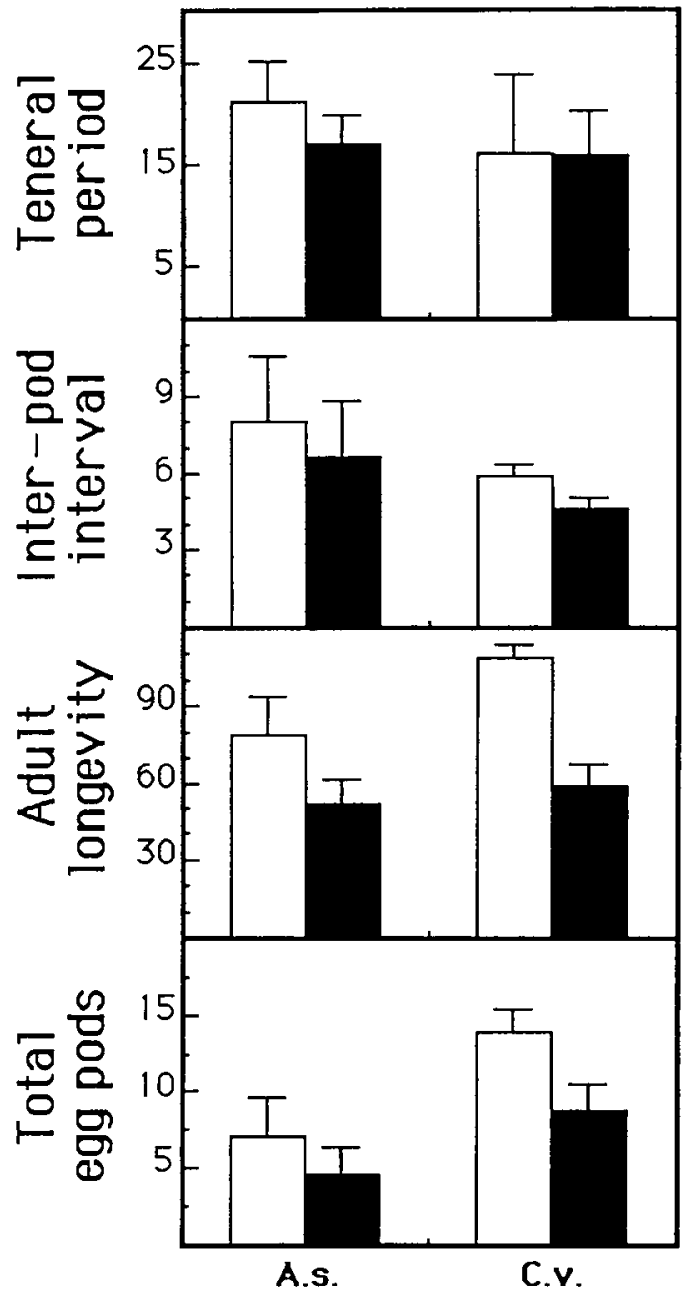

Species

FIG. 10. The effect of maturation time on female life history characteristics. Teneral period is the number of days after adult molting before the onset of reproduction. Interpod interval for a female is the mean number of days between successive egg pods, with lower interpod intervals implying a more rapid rate of reproduction. Data for control females are given by the solid bars while the open bars are for early females.

and $C$. viridifasciata. Late hatching nymphs lack time and adequate growing conditions to reach body sizes necessary to overwinter successfully. Similar size-dependent overwinter survival has been seen in other insects (e.g., Ohgushi, 1986). The mechanism of size-dependent mortality in A. sulphurea and $C$. viridifasciata remains to be studied. Small size, per se, is no barrier to overwinter survival, as first instar juveniles are com- mon overwintering stages in many groups of insects (e.g., Scott and Epstein, 1987; Danks, 1987). Comparing A. sulphurea and $C$. viridifasciata nymphs brought into the greenhouse in February to those maintained outside until spring shows that weight loss had already occurred by midwinter (Fig. 7), but most mortality occurred later. This argues against overwinter mortality being a simple function of loss of weight or fat reserves. A possible reason for the late winter mortality could involve repeated freezing and thawing of the nymphs during the transition from winter to spring.

Due to the limited range of hatching dates under normal conditions, most control nymphs grew to a prewinter body size where size-dependent effects on overwinter mortality were less apparent (Fig. 6). Because of this, the delayed hatching treatment was critical in providing evidence for the importance of size-dependent overwinter mortality in the life cycles of $A$. sulphurea and $C$. viridifasciata. It is important, therefore, that the patterns of survival among delayed nymphs not be an artifact of the experimental treatment. Although the refrigeration treatment used to delay hatching resulted in somewhat fewer nymphs hatching per pod, delayed nymphs were similar to controls with respect to hatchling dry weight, hatching phenology (once delay duration was accounted for), fall growth as a function of hatching date and overwinter survival. The only difference in the growth and survival of control and delayed nymphs was the smaller prewinter weight of delayed C. viridifasciata nymphs as a function of hatching date, which can be explained in terms of seasonal increases in offspring size produced by $C$. viridifasciata females (Landa, 1989). Because delayed nymphs of a given hatching date were produced earlier in the season than controls hatching at the same time, they would have had a smaller initial weight and would be expected to grow more slowly.

Seasonal declines in offspring fitness are common in a number of groups, but the underlying mechanisms are often different. For $A$. sulphurea and $C$. viridifasciata, the declines are primarily due to abiotic effects on juvenile survival, with secondary effects on the timing and amount of adult repro- 
duction. For Melanoplus sanguinipes, a grasshopper which overwinters as eggs, juvenile survival is little affected by hatching date, but late hatching nymphs produce late adults which have less time to reproduce before killing frosts end the breeding season in the fall (Pickford, 1960). Juvenile growth and survival decline with hatching date in the sycamore aphid, Drepanosiphum platanoides, due to seasonal declines in food quality (Dixon, 1976). Finally, offspring fitness declines with emergence date for many plants, as early emerging individuals monopolize resources and suppress later emerging individuals (e.g., Cook, 1980). Knowledge of these seasonal changes in individual fitness is necessary for understanding the selective pressures shaping the phenologies of species in seasonal environments.

\section{Selection for Early Reproduction}

Due to the lack of embryonic diapause in A. sulphurea and C. viridifasciata, date of hatching has a strong positive correlation with oviposition date. Because of this relationship, and the seasonal declines in offspring fitness, eggs produced late in the breeding season contribute less to parental fitness. This should select for early reproduction by females of these two species, in order to promote early hatching and greater offspring survival. Due the curvilinear relationship between oviposition date and hatching date, however, the advantage gained by moving reproduction to earlier dates varies seasonally. Late in the season, reproducing one day earlier results in hatching occurring more than one day earlier, because of the decrease in embryonic development time at midseason compared to late season. Embryonic development times are longer early in the season compared to midseason, however, lessening the hatching date advantage to very early reproduction. It is suggestive that the bulk of oviposition under natural conditions occurs during the period of minimum development time.

The strength of selection for early reproduction will also vary from year to year. The fall temperature regime is critical in determining the amount of prewinter growth attained by nymphs, and therefore the probability of overwinter survival, following any given date of hatching. Between year vari-

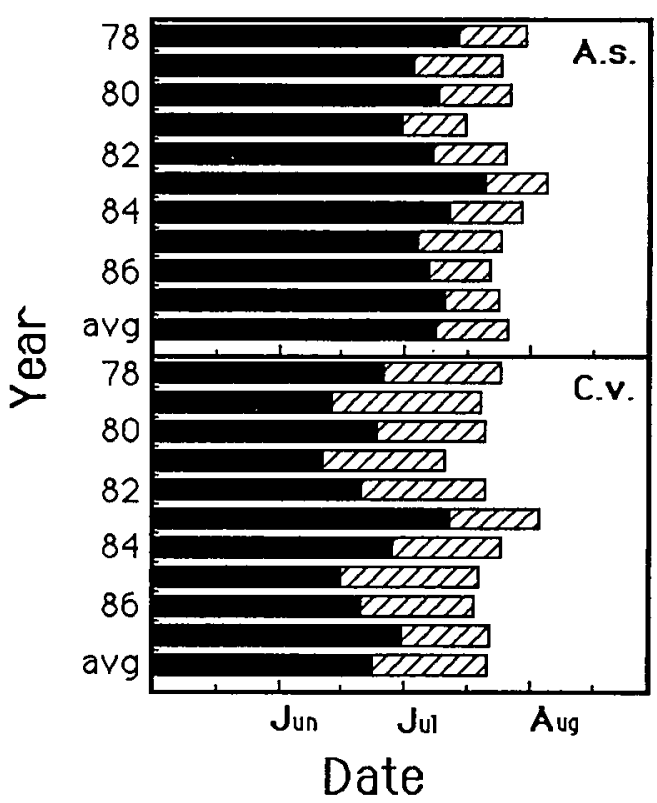

FIG. 11. Predicted last dates of oviposition for nymphs to reach critical body sizes before winter. These dates are based on historical weather data and the observed responses of embryonic development and nymphal growth to temperature. Solid bars give the ranges of dates which would result in nymphs reaching $90 \mathrm{mg}$ or more before winter, while the cross-hatched bars give the cut-off dates for $40 \mathrm{mg}$ nymphs.

ations in fall temperatures raise the possibility that late nymphs, which have little or no chance of survival during normal years, might be able to survive and reproduce in years with warm falls. Conversely, years with early winters would decrease more abruptly the relative fitness of late nymphs. Using historical weather records for the years 1978 through 1987, along with the relationships of embryonic development and nymphal growth to temperature, I calculated the last oviposition dates that would allow nymphs to attain prewinter weights of $40 \mathrm{mg}$ (below which there is little chance of survival) or $90 \mathrm{mg}$ (above which survival varies little with body size). These oviposition dates varied over a range of 3 to 4 weeks among years in both species (Fig. 11). There was no temporal correlation between successive years for predicted last dates of oviposition to reach either body size $(P \gg 0.05$ for both species, Durbin-Watson test). This between-year unpredictability of the end of the breeding season may lead to genetic variation or phenotypic plasticity in repro- 
ductive characters. $C$. viridifasciata was slightly more variable in predicted cutoff dates and, because of slower growth as a function of degree-days, $C$. viridifasciata cutoff dates were uniformly earlier than for A. sulphurea. The stronger selection against late hatching in $C$. viridifasciata may explain the earlier oviposition phenology (Fig. 1) and the more rapid embryonic development (Fig. 2) in this species compared to A. sulphurea.

\section{Adult Life History Traits}

The relationships between molting date and hatching date for males and females of both species show that late hatching individuals tend to catch up to early hatchers; the slopes of these regressions are all less than 1. Male molting date is less delayed by later hatching than female molting date, and $C$. viridifasciata individuals catch up better than $A$. sulphurea individuals. These relationships can be understood in terms of differential selection on the timing of maturation among these groups. Because of the stronger selection for early reproduction in $C$. viridifasciata, late maturing $C$. viridifasciata females would be at a greater disadvantage compared to early $C$. viridifasciata females, than would late $A$. sulphurea females compared to early $A$. sulphurea females, and should be under stronger selection not to delay maturation. In both species, males would be under stronger selection not to delay maturation than females, because male fitness is a function of access to females and late maturing males would find all the females already mated.

Interestingly, the shorter development times of late hatching individuals do not come at the expense of smaller body sizes. This may be because size-dependent overwinter mortality allows only the largest of the late hatching nymphs to survive the winter, or because late hatching individuals have warmer spring growing conditions during the final instar, when the bulk of insect growth occurs. Size-dependent maturation has been seen in some other insects [e.g., Nijhout, 1975; Blakely and Goodner, 1978; Lounibos, 1979; but not in the grasshopper Locusta migratoria (Clarke and Langley, 1962)], and has been related to highly variable juvenile growth rates and the need for a critical level of resources for adult dispersal and survival (Blakely, 1981). These factors do not seem applicable to $A$. sulphurea and $C$. viridifasciata and, given the strong selection for early reproduction, it is unclear why late hatching individuals do not show more of a tradeoff between adult body size and maturation time (Policansky, 1983; Stearns and Crandall, 1984).

For both species, late molting females reproduce at a more rapid rate and live for a shorter time after molting. The effects of molting date on female reproductive rate and adult longevity are consistent with selection for early reproduction, in a situation where there is a cost to reproduction (Hirschfield and Tinkle, 1975; Calow, 1979; Reznick, 1985). Selection for early reproduction, due to the seasonal declines in offspring fitness, should be more intense for females that mature late in the season, compared with early maturing females. If there is a physiological cost of reproduction, then a more rapid reproductive rate among late females could directly decrease their longevity. Rapid reproductive rates among late females would still be favored, even though the associated shorter longevity leads to lower total fecundity, because late season egg pods contribute little or nothing to parental fitness. Early females could maximize total fecundity by reproducing at a more moderate rate and living longer, producing more total offspring which would still have sufficient time to grow large enough to overwinter.

There are alternative potential explanations, in addition to the seasonal declines in offspring fitness, that may explain the changes in female reproductive rate and longevity with molting date. If mortality rates due to extrinsic factors, such as predation or heat and water stress, increase during the summer, then late females would have a lower life expectancy after molting and may be expected to reproduce at a more rapid rate. In addition, the higher temperatures later in the season could directly increase reproductive rate and decrease life span, as has been reported for other species of grasshoppers (Uvarov, 1966, 1977). It is uncertain, therefore, whether the seasonal changes in reproduction and longevity represent adaptive phenotypic plasticity for al- 
location to reproduction and survival, unavoidable consequences of changing environmental conditions or both.

\section{CoNCLUSIONS}

This study highlights the role of seasonal changes in abiotic conditions for the evolution of phenology in these nymph-overwintering grasshoppers and, in particular, the effects of size-dependent overwinter mortality. Without experimental manipulation, the fitness consequences of hatching date variation would have been less obvious. Although other factors, such as seasonal partitioning among competitors (Shapiro, 1975; Onsager, 1986) or avoidance of natural enemies, may potentially affect life cycle timing in these two species, the observed patterns of phenology, as well as seasonal variation in adult female life-history traits, are consistent with responses to seasonal changes in offspring growth and survival imposed by abiotic conditions. Seasonal changes in growth, survival and reproduction of individuals, in turn, have population level consequences. Although these species lack the synchronizing effect of embryonic diapause, size-dependent overwinter mortality, maturation at younger ages by late-hatching individuals and the shorter longevity of late-maturing adults all act to synchronize the populations of $A$. sulphurea and $C$. viridifasciata.

\section{ACKNOWLEDGMENTS}

I especially thank L. Landa, for assistance with field work under both pleasant and trying circumstances. The staff of the Matthei Botanical Gardens provided facilities, assistance and general understanding toward someone wanting to grow grasshoppers instead of plants. This manuscript benefited from comments by M. Geber, B. Rathcke, J. Moorehead, D. Reznick, L. Rowe, and two anonymous reviewers.

\section{Literature Cited}

Alexander, G. 1967. Cold-hardiness in overwintering juvenile grasshoppers. Entomol. News 78:147154.

ARNOLD, S. J. 1986. Limits on stabilizing, disruptive, and correlational selection set by the opportunity for selection. Am. Nat. 128:143-146.

Arnold, S. J., AND M. J. WADE. 1984a. On the measurement of natural and sexual selection: Theory. Evolution 38:709-719. 1984b. On the measurement of natural and sexual selection: Applications. Evolution 38:720734.

BASKIN, J. M., AND C. C. BASKIN. 1972. Influence of germination date on survival and seed production in a natural population of Leavenworthia stylosa. Am. Midl. Nat. 88:318-323.

BLAKELY, N. 1981. Life history significance of sizetriggered metamorphosis in milkweed bugs ( $\mathrm{On}$ copeltus). Ecology 62:57-64.

Blakely, N., AND S. R. GoOdNer. 1978. Size-dependent timing of metamorphosis in milkweed bugs (Oncopeltus) and its life history implications. Biol. Bull. 155:499-510.

BoyCE, M. S. 1979. Seasonality and patterns of natural selection for life histories. Am. Nat. 114:569583.

Calow, P. 1979. The cost of reproduction-a physiological approach. Biol. Rev. 54:23-40.

CAMPBell, D. R. 1989. Measurements of selection in a hermaphoditic plant: Variation in male and female pollination success. Evolution 43:318-334.

Cantrall, I. J. 1943. The ecology of the Orthoptera and Dermaptera of the George Reserve, Michigan. Misc. Publ., Mus. Zool., Univ. Mich. 54:1-182.

Cavers, P. B., AND M. G. Steel. 1984. Patterns of change in seed weight over time on individual plants. Am. Nat. 124:324-335.

Clarke, K. U., AND P. LANGley. 1962. Factors concerned in the initiation of growth and moulting in Locusta migratoria L. Nature 194:160-162.

Cook, R. E. 1980. Germination and size-dependent mortality in Viola blanda. Oecologia 47:115-117.

Crespi, B. J., AND F. L. BooksteIN. 1989. A pathanalytical model for the measurement of selection on morphology. Evolution 43:18-28.

DANKs, H. V. 1987. Insect Dormancy: An Ecological Perspective. Biological Survey of Canada, Ottawa, ON, Canada.

DEAN, J. M. 1982. Control of diapause induction by a change in photoperiod in Melanoplus sanguinipes. J. Ins. Physiol. 28:1033-1040.

Dingle, H., T. A. Mousseau, AND S. M. SCOTt. 1990. Altitudinal variation in life cycle syndromes of California populations of the grasshopper, Melanoplus sanguinipes (F.). Oecologia 84:199-206.

Dixon, A. F. G. 1976. Timing of egg hatch and viability of the sycamore aphid Drepanosiphum platanoides (Schr.), at bud burst of sycamore, Acer psuedoplatanus L. J. Anim. Ecol. 45:593-603.

DOWNHOWER, J. F., L. S. BLUMER, AND L. BROWN. 1987. Opportunity for selection: An appropriate measure for evaluating variation in the potential for selection? Evolution 41:1395-1400.

FeENY, P. P. 1970. Seasonal changes in oak leaf tannins and nutrients as a cause of spring feeding by winter moth catepillers. Ecology 51:565-581.

ForREST, T. G. 1986. Oviposition and maternal investment in mole crickets (Orthoptera: Gryllotalpidae): Effects of season, size and senescence. Ann. Entomol. Soc. Am. 79:918-924.

Gangwere, S. K., F. C. Evans, and M. L. Nelson. 1976. The food-habits and biology of Acrididae in an old-field community in southeastern Michigan. Great Lakes Entomol. 9:83-123.

Giesel, J. T. 1976. Reproductive strategies as ad- 
aptations to life in temporally heterogeneous environments. Annu. Rev. Ecol. Syst. 7:57-79.

HaRveY, G. T. 1977. Mean weight and rearing performance of successive egg clusters of eastern spruce budworm (Lepidoptera: Tortricidae). Canad. Entomol. 109:487-496.

HASTINGS, A. 1984. Evolution in a seasonal environment: Simplicity lost? Evolution 38:350-358.

Hilbert, D. W., AND J. A. Logan. 1983. Empirical model of nymphal development for the migratory grasshopper, Melanoplus sanguinipes (Orthoptera: Acrididae). Environ. Entomol. 12:1-5.

HirschFIELD, M. F., AND D. W. TINKLE. 1975. Natural selection and the evolution of reproductive effort. Proc. Nat. Acad. Sci. USA 72:2227-2231.

Hubbell, S. P., AND L. K. Johnson. 1987. Environmental variance in lifetime mating success, mate choice and sexual selection. Am. Nat. 129:91-112.

JAYNE, B. C., AND A. F. BENNETT. 1990. Selection on locomotor performance capacity in a natural population of garter snakes. Evolution 44:1204-1229.

KALISZ, S. 1986. Variable selection on the timing of germination in Collinsia verna (Scrophulariaceae). Evolution 40:479-491.

Koening, W. D., and S. S. Albano. 1987. Lifetime reproductive success, selection and the opportunity for selection in the white-tailed skimmer, Plathemis lydia (Odonata: Libellulidae). Evolution 41:22-36.

LACEY, E. P. 1982. Timing of seed dispersal in Daucus carota. Oikos 39:83-91.

LANDA, K. B. 1989. Seasonal variation of life-history traits in the nymph-overwintering grasshoppers, Arphia sulphurea and Chortophaga viridifasciata. University of Michigan: Ann Arbor, Ph.D. Dissertation.

LANDE, R., AND S. J. ARnold. 1983. The measurement of selection on correlated charcters. Evolution 37:1210-1226.

LouniBos, L. P. 1979. Temporal and spatial distribution, growth and predatory behavior of Toxorhynchites brevipalpis (Diptera: Culcidae) on the Kenya coast. J. Anim. Ecol. 48:213-236.

MAllet, J., AND N. H. BARTON. 1989. Strong natural selection in a warning-color hybrid zone. Evolution 43:421-431.

MARks, M., ANd S. Prince. 1981. Influence of germination date on survival and fecundity in wild lettuce Lactuca serriola. Oikos 36:326-330.

Mitchell-Olds, T., AND R. G. Shaw. 1987. Regression analysis of natural selection: Statistical inference and biological interpretation. Evolution 41: 1149-1161.

Nishour, M. F. 1975. A threshold size for metamorphosis in the tobacco hornworm, Manduca sexta (L.). Biol. Bull. 149:214-225.

OHGUSH, T. 1986. Population dynamics of an herbivorous lady beetle, Henosepilachna niponica, in a seasonal environment. J. Anim. Ecol. 55:861879.

ONSAGER, J. A. 1986. Stability and diversity of grasshopper species in a grassland community due to temporal heterogeneity. Proc. Pan Am. Acrid. Soc. 4:101-109.

OTTE, D. 1981. The North American Grasshoppers. Vol 1: Gomphocerinae and Acridinae. Harvard Univ. Press, Cambridge, MA, USA.
1984. The North American Grasshoppers. Vol 2: Oedipodinae. Harvard Univ. Press, Cambridge, MA, USA.

PICKFORD, R. 1960. Survival, fecundity and population growth of Melanoplus bilituratus (W1k.) (Orthoptera: Acrididae) in relation to date of hatching. Can. Entomol. 92:1-10.

. 1976. Embryonic growth and hatchability of eggs of the two-striped grasshopper, Melanoplus bivittatus (Orthoptera: Acrididae), in relation to date of oviposition and weather. Can. Entomol. 108: 621-626.

Policansky, D. 1983. Size, age and demography of metamorphosis and sexual maturation in fishes. Am. Zool. 23:57-63.

RAUSCHER, M. D., AND E. L. SIMMS. 1989. The evolution of resistance to herbivory in Ipomoea purpurea. 1. Attempts to detect selection. Evolution 43:563-572.

REZNICK, D. 1985. Costs of reproduction: An evaluation of the empirical evidence. Oikos 44:257267.

RoFF, D. 1983. Phenological adaptation in a seasonal environment: $A$ theoretical perspective, pp. 251270. In V. Brown and I. Hodek (eds.), Diapause and Life-Cycle Strategies of Insects. Junk, The Hague, Netherlands.

SAS INSTITUTE. 1985. SAS User's Guide: Statistics, Version 5 Edition. SAS Inst. Inc., Cary, NC, USA.

SCHEINER, S. M. 1989. Variable selection along a successional gradient. Evolution 43:548-562.

SChemske, D. W., AND C. C. Horvitz. 1989. Temporal variation in selection on a floral character. Evolution 43:461-465.

SCHLUTER, D. 1988. Estimating the form of natural selection on a quantitative trait. Evolution 42:849861.

Scott, J. A., AND M. E. Epstein. 1987. Factors affecting phenology in a temperate insect community. Am. Midl. Nat. 117:103-118.

ShapIRo, A. M. 1975. The temporal component of butterfly species diversity, pp. 181-195. In Cody, M. L., and J. M. Diamond (eds.), Ecology and Evolution of Communities. Harvard Univ. Press, Cambridge, MA, USA.

SINERvo, B. 1990. The evolution of maternal investment in lizards: And experimental and comparative analysis of egg size and its effects on offspring performance. Evolution 44:279-294.

SMITH, T. B. 1990. Natural selection on bill characters in the two bill morphs of the African finch, Pyrenestres ostrinus. Evolution 44:832-842.

Stearns, S. C., AND R. E. Crandall. 1984. Plasticity for age and size at sexual maturity: A life-history response to unavoidable stress, pp. 13-33. In Potts, G. W., and R. J. Wootten (eds.), Fish Reproduction: Strategies and Tactics. Academic Press, London, UK.

Tauber, M. J., C. A. TAuber, And S. Masaki. 1986. Seasonal Adaptations in Insects. Oxford Univ. Press, N.Y., USA.

TAYLOR, F. 1980a. Timing in the life histories of insects. Theor. Popul. Biol. 18:1 12-124.

. 1980b. Optimal switching to diapause in relation to the onset of winter. Theor. Popul. Biol. 18:125-133. 
TAYLOR, F., AND R. Karban (eds.). 1986. The Evolution of Insect Life Cycles. Springer-Verlag, N.Y., USA.

Uvarov, B. P. 1966. Grasshoppers and Locusts. A Handbook of General Acridology. Vol 1: Anatomy, physiology, development, phase polymorphism and introduction to taxonomy. Cambridge Univ. Press, London, UK.

. 1977. Grasshoppers and Locusts. A Handbook of General Acridology. Vol 2: Behavior, ecology, biogeography, population dynamics. Centre for Overseas Pest Research, London, UK.

WADE, M. J., AND S. Kalisz. 1989. The additive partitioning of selection gradients. Evolution 43: $1567-1569$.
1990. The causes of natural selection. Evolution 44:1947-1955.

Weis, A. E., AND W. L. Gorman. 1990. Measuring selection on reaction norms: An exploration of the Eurosta-Solidago system. Evolution 44:820-831.

WELlington, W. G. 1965. Some maternal influences on progeny quality in the western tent caterpillar, Malacosoma pluviale (Dyar). Can. Entomol. 97:114.

WhItMan, D. W. 1986. Developmental thermal requirements for the grasshopper Taenipoda eques (Orthoptera: Acrididae). Ann. Entomol. Soc. Am. 79:711-714.

Corresponding Editor: D. Reznick 